\title{
Prevalence of GMC performance assessments in the United Kingdom: a retrospective cohort analysis by country of medical qualification
}

\author{
L. Mehdizadeh ${ }^{1}$, H. W. W. Potts ${ }^{2 *}$, A. Sturrock ${ }^{1}$ and J. Dacre ${ }^{3}$
}

\begin{abstract}
Background: The demographics of doctors working in the UK are changing. The United Kingdom (UK) has voted to leave the European Union (EU) and there is heightened political discourse around the world about the impact of migration on healthcare services. Previous work suggests that foreign trained doctors perform worse than UK graduates in postgraduate medical examinations. We analysed the prevalence by country of primary medical qualification of doctors who were required to take an assessment by the General Medical Council (GMC) because of performance concerns.

Methods: This was a retrospective cohort analysis of data routinely collected by the GMC. We compared doctors who had a GMC performance assessment between 1996 and 2013 with the medical register in the same period. The outcome measures were numbers experiencing performance assessments by country or region of medical qualification.

Results: The rate of performance assessment varied significantly by place of medical qualification and by year; $X^{2}(17)=188, p<0.0001$, pseudo- $R^{2}=15 \%$. Doctors who trained outside of the UK, including those trained in the European Economic Area (EEA), were more likely to have a performance assessment than UK trained doctors, with the exception of South African trained doctors.

Conclusions: The rate of performance assessment varies significantly by place of medical qualification. This is the first study to explore the risk of performance assessment by individual places of medical qualification. While concern has largely focused on the competence of non-EEA, International Medical Graduates, we discuss implications for how to ensure European trained doctors are fit to practise before their medical licence in the UK is granted. Further research is needed to investigate whether these country effects hold true when controlling for factors like doctors' sex, age, length of time working in the UK, and English language skills. This will allow evidencebased decisions to be made around the regulatory environment the UK should adopt once it leaves the EU. Patients should be reassured that the vast majority of all doctors working in the UK are competent.
\end{abstract}

Keywords: Primary medical qualification, General Medical Council, Performance assessment, Cohort study, Brexit

* Correspondence: h.potts@ucl.ac.uk

${ }^{2}$ UCL Institute of Health Informatics, 222 Euston Road, London NW1 2DA, UK

Full list of author information is available at the end of the article

(c) The Author(s). 2017 Open Access This article is distributed under the terms of the Creative Commons Attribution 4.0 International License (http://creativecommons.org/licenses/by/4.0/, which permits unrestricted use, distribution, and reproduction in any medium, provided you give appropriate credit to the original author(s) and the source, provide a link to the Creative Commons license, and indicate if changes were made. The Creative Commons Public Domain Dedication waiver (http://creativecommons.org/publicdomain/zero/1.0/) applies to the data made available in this article, unless otherwise stated. 


\section{Background}

The demographics of United Kingdom (UK) doctors has been changing in recent years and may change further following a referendum decision to leave the European Union (EU) [1]. We are in a period of heightened political discourse about immigration and supranational trade agreements across the developed world, with many implications for health services. The migration of doctors from low and middle income countries to high income countries in North America and Western Europe is well documented [2-4]. Political rhetoric has raised concerns for immigrant doctors in, for example, the United States [5-7]. With developed countries often dependent on healthcare professionals who trained abroad [8], the question of how to assess qualifications from another country is significant. Healthcare services need to ensure that staff are competent and that mechanisms to ensure this are transparent to the public. At present, in the UK, doctors who qualified in the rest of the EU, the wider European Economic Area (EEA) or in former EEA member Switzerland can practise without further assessment of their clinical skills. As shorthand, we refer to these below as EEA doctors. Those trained elsewhere must pass the Professional and Linguistic Assessments Board (PLAB) test before practising: we refer to these non-EEA, international medical graduates as IMGs. See Table 1 for a summary. The regulatory context in the future is as yet unknown $[9,10]$.

There has been a dramatic change in the pattern of non-UK trained doctors joining the medical register in recent years. A higher proportion of graduates from the EEA, particularly Spain and Greece, joined the medical register compared to IMGs [5]. Historically, the proportion of doctors in the UK who were IMGs was always higher than EEA doctors. While EEA doctors only represented a tenth of the total medical population in 2013, their proportional increase is likely to be due to the economic downturn in southern Europe and the expansion of the EEA [6]. Similar trends have been noted elsewhere, including Germany [11] and Ireland [2]. Meanwhile, changes to the UK's immigration policy in 2010 made it more difficult for IMGs to get an employment visa, perhaps explaining the decrease in the proportion joining the register [12].

The General Medical Council (GMC) are the UK's medical regulatory body responsible for protecting, promoting and maintaining the health and safety of the public. As part of this role, the GMC can investigate the fitness to practise of doctors working in the UK about which they receive complaints to ensure proper standards in medical practice are upheld. Where the concerns relate to an aspect of the doctor's performance (such as a basic lack of knowledge, poor clinical judgement, inappropriate prescribing, tendency to use outdated techniques or poor record keeping), they may be required to take a performance assessment. A performance assessment may form one part of a wider investigation into a doctor's fitness to practise.

The GMC holds data on all doctors who have undergone performance assessment as part of a Fitness to Practise investigation. Doctors under performance assessment usually undergo a peer review and test of competence $[13,14]$. The test of competence is used to identify potential gaps in a doctor's knowledge base and/ or their clinical skills. This includes a written knowledge test using Single Best Answer format and an Objective Structured Clinical Examination closely tailored to the doctor's grade, speciality and clinical work. The marks achieved by the doctor under investigation are compared to the range of marks achieved by a comparison group of doctors who have volunteered to take a similar test in the same specialty [15]. Trained investigators at the

Table 1 UK licensing arrangements (while the UK is a member of the European Union)

\begin{tabular}{|c|c|c|c|}
\hline $\begin{array}{l}\text { Shorthand used } \\
\text { in this paper }\end{array}$ & Category and notes & Countries (listed by population size) & $\begin{array}{l}\text { Licensing arrangements for } \\
\text { doctors working in the UK }\end{array}$ \\
\hline UK doctors & $\begin{array}{l}\text { UK: current member of EU and } \\
\text { EEA; due to leave EU; EEA } \\
\text { membership plans unknown }\end{array}$ & UK & $\begin{array}{l}\text { Can practise in the UK if qualified } \\
\text { in one of these countries }\end{array}$ \\
\hline \multirow[t]{3}{*}{ EEA doctors } & $\begin{array}{l}\text { Remainder of the European Union; } \\
\text { all also in the EEA }\end{array}$ & $\begin{array}{l}\text { Germany, France, Italy, Spain, Poland, Romania, } \\
\text { Netherlands, Belgium, Greece, Czech Rep., } \\
\text { Portugal, Sweden, Hungary, Austria, Bulgaria, } \\
\text { Denmark, Finland, Slovakia, Ireland, Croatia, } \\
\text { Lithuania, Slovenia, Latvia, Estonia, Cyprus, } \\
\text { Luxembourg, Malta }\end{array}$ & \\
\hline & $\begin{array}{l}\text { Remainder of the EEA; not in } \\
\text { the EU }\end{array}$ & Norway, Iceland, Liechtenstein & \\
\hline & Former EEA member & Switzerland & \\
\hline $\begin{array}{l}\text { International } \\
\text { medical } \\
\text { graduates (IMGs) }\end{array}$ & Rest of the world & Rest of the world & $\begin{array}{l}\text { Required to pass the Professional } \\
\text { and Linguistic Assessments Board } \\
\text { (PLAB) test }\end{array}$ \\
\hline
\end{tabular}


GMC use all of the above aspects of a performance assessment to reach a judgement about a doctor's fitness to practise. These data are collated from the LRMP and portfolios of each doctor that contains their personal information, qualifications and details around their employment history and clinical work.

While the UK relies on foreign trained doctors to fill shortages in the health service [8], their clinical performance has been the subject of concern in recent years, arguably unfairly [16]. Poorer performance of IMGs in postgraduate examinations in the UK has been reported in numerous studies when compared to UK graduates $[17,18]$. We also know that IMGs are more likely to be complained about to the GMC and receive more severe disciplinary action than other doctors in Fitness to Practise investigations $[19,20]$. However concern has also grown around the performance of European trained doctors $[20,21]$. This has been highlighted by high profile cases such as the German-trained doctor who killed a patient during his first locum shift in the UK, and a Bosnian-trained obstetrician who caused the death of a new-born baby [22]. Evidence shows these are not isolated incidents. One study analysed results on part one of the Royal College of Anaesthetists examination and produced a list of countries of primary medical qualification (PMQ) that performed worse than UK graduates. While graduates from Egypt, Iraq and Pakistan performed worse, so did graduates from certain European countries [23]. GMC statistics also report that men who graduated from a European medical school are at greater risk of being complained about to and/or disciplined by the GMC [19]. In GMC Fitness to Practise hearings between 2009 and 2012, higher proportions of EEA doctors were found to be impaired in their performance compared to IMGs and UK graduates [24-27]. Further, an earlier study that analysed erasures and suspensions from the List of Registered Medical Practitioners (LRMP) by country of medical qualification, found that European countries made up half of the top 20 countries that were more likely than the UK to have their graduates be erased or suspended by the GMC [28].

We note that this contrasts with the situation in the US where a recent study found that patients treated by international graduates had lower mortality than patients cared for by US graduates [29] and international graduates perform better in some exams [30].

\section{Aim and purpose of study}

Given the recent and likely forthcoming changes to the UK's medical register and the increasing concern around the performance of non-UK medical graduates, we compared the demographics of the UK's medical register with doctors who had undertaken a performance assessment with the GMC to determine whether country of training predicts performance assessments and, if so, whether this might be explained by other factors. We focussed on the prevalence of GMC performance assessments by country of PMQ. Data made available by the GMC allowed us to control for some additional factors and examine performance in more detail than previous studies.

\section{Methods}

This was a retrospective cohort analysis of data routinely collected by the GMC.

We compared two sets of data:

1) a cohort of doctors who had a performance assessment between 1996 and 2013.

2) the medical register (LRMP) between 1996 and 2014.

Performance assessment data was only available up to 2013, but LRMP data was additionally available for 2014 . The cohorts were compared according to: sex, country and year of primary medical qualification, specialty and age.

\section{Variables}

The data on sex was complete for both cohorts. In order to plot trends over time, we analysed the year the GMC received an enquiry about each doctor; this date marked the start of their performance investigation. There were 29 cases for which the enquiry year was missing. We also analysed the medical register at each year end.

Data was available for the country and year doctors gained their PMQ from. Data was also recorded on specialty and age band.

We did not have data on the outcome for those under performance investigation. Investigations take some time to complete and many were not complete at the time of data collection. From other GMC data, we know that among individuals who complete tests of competence, over half receive some kind of sanction, with roughly equal numbers being cleared without sanction or voluntarily withdrawing from the register [31].

\section{Data analysis}

We analysed the demographics of the two cohorts by comparing frequency data. We focused our analysis on doctors' PMQ country, initially in the context of changes to the medical register over time. We then compared the rates of performance assessments over time by PMQ country using negative binomial regression. This allows us to consider country differences while adjusting for the significant changes in the rate of assessments over time. 


\section{Results}

\section{Comparing performance assessment cases with medical} register

We compared the population of doctors under performance assessment with doctors who were on the medical register. We show descriptive statistics in order to provide due context for the analysis by country of training. Results for the earliest (1996) and latest (2014) years in the data are shown in Table 1. Men and black minority ethnic doctors were over represented as compared to the medical register. More than $80 \%$ of doctors under performance assessment were above 40 years old, as compared to the medical register where a large proportion of doctors are under 40. A significantly higher number of surgeons and general practitioners had a performance assessment as compared to the proportion listed on the medical register as of 2014 (Table 2).

Table 2 Comparing demographics of doctors under GMC's performance assessment with UK medical register between years 1996-2014

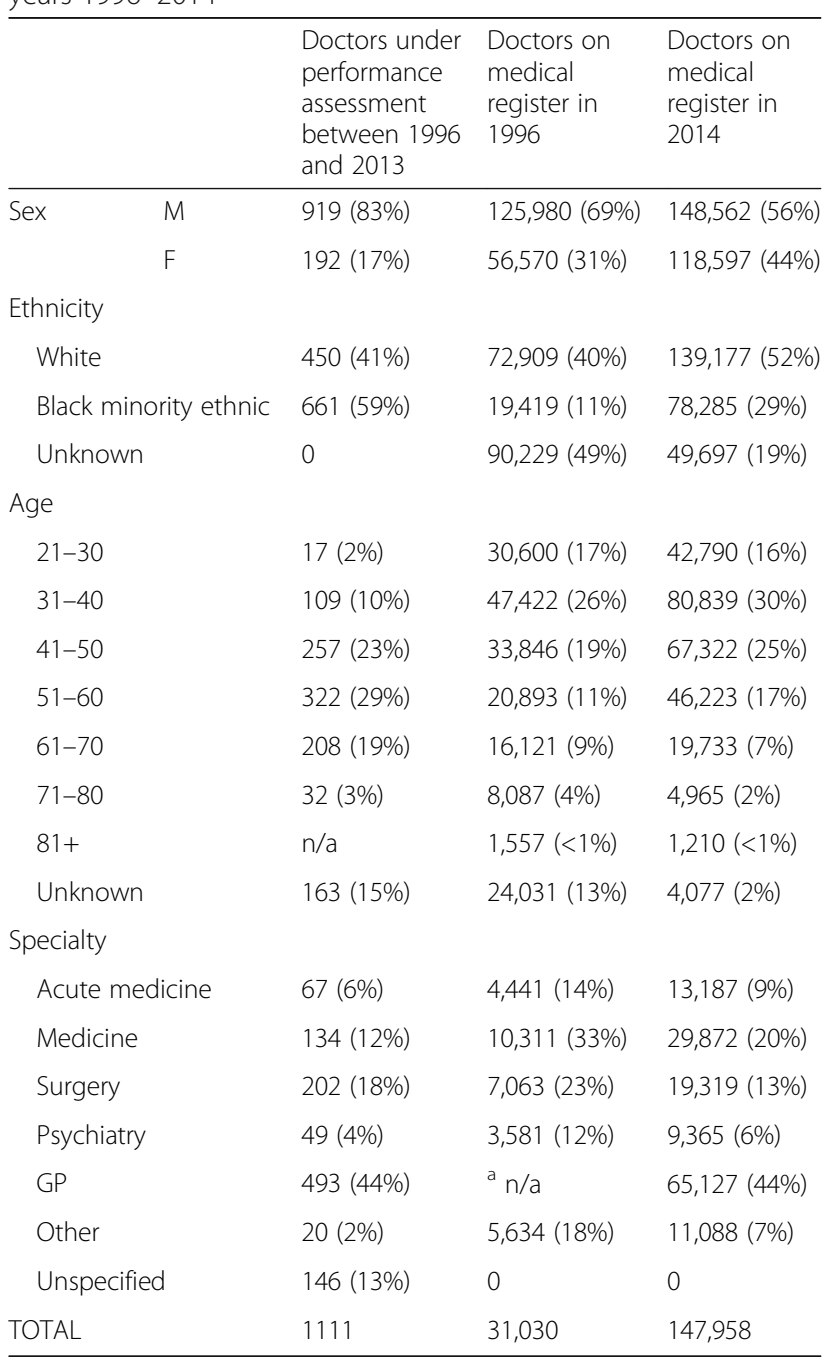

${ }^{a}$ GP register only began in 2006
Comparing PMQ between performance assessment cases and medical register

Doctors on the medical register in 2014, the most recent year of the data, received their PMQ from 149 different states or territories. Doctors under performance assessment from 1996 to 2013 qualified from 58 states or territories. Table 3 shows the 25 countries with the most performance assessments. Doctors on the medical register in 2014 most frequently graduated from the UK, India and Pakistan. The highest number of performance assessments was also conducted on UK, Indian and Pakistan graduates (Table 3 ).

\section{Changes to the medical register over time}

It was necessary to place the performance assessment data in the context of changes that have happened to the medical register between 1996 and 2013. The rate of assessments depends on a denominator, the number of doctors trained in different countries, that has been changing rapidly. We summarise these changes in Table 4 and compared them to the proportion of performance assessments that have been conducted on doctors qualifying in the same regions. This gave us a sense of which places of qualification are over and underrepresented in the GMC's performance assessments when compared to the medical register. Based on the data available, we decided to analyse the data for the following 16 countries and categories:

I). the UK

II). the ten countries with the highest numbers of registered doctors in 2014

III). the ten countries with highest number of performance assessments (which adds Bangladesh, Iraq and Sri Lanka in addition to the above)

IV).European Union (EU) 2004 accession states as a block, i.e. countries that joined the EU in 2004, namely Cyprus, Czech Republic, Estonia, Hungary, Latvia, Lithuania, Malta, Poland, Slovakia, and Slovenia

V). a combined category for all other current EEA states not otherwise covered plus Switzerland (i.e., countries excluded from the Professional and Linguistics Assessment Board examination)

VI).rest of the world (ROW)

Small numbers prevented us from considering other countries in detail.

The total number of UK trained doctors has increased on the medical register by $31 \%$ since 1996 (from 125,486 to 164,691 , Table 4). For other countries, the largest absolute increase is Indian-trained doctors, up 12,361(97\%), with the largest fall being Australian-trained, down to 2868 (from 4834 in 1996 
Table 3 Comparing the UK medical register with GMC's performance assessment cases against the most frequent 25 countries of PMQ

\begin{tabular}{|c|c|c|c|c|c|}
\hline Rank & Country of PMQ & $\begin{array}{l}\text { Number of registered } \\
\text { Doctors (2014) }\end{array}$ & Rank & Country of PMQ & $\begin{array}{l}\text { Number of performance } \\
\text { assessment } \\
\text { cases } \\
\text { (1996-2013) }\end{array}$ \\
\hline 1 & United Kingdom & 169,239 & 1 & United Kingdom & 332 \\
\hline 2 & India & 25,001 & 2 & India & 242 \\
\hline 3 & Pakistan & 9786 & 3 & Pakistan & 61 \\
\hline 4 & South Africa & 5276 & 4 & Nigeria & 47 \\
\hline 5 & Nigeria & 4185 & $5=$ & Egypt & 45 \\
\hline 6 & Ireland & 4042 & $5=$ & Germany & 45 \\
\hline 7 & Italy & 3539 & 7 & Iraq & 30 \\
\hline 8 & Greece & 3423 & 8 & Ireland & 28 \\
\hline 9 & Egypt & 3336 & 9 & Bangladesh & 23 \\
\hline 10 & Germany & 3241 & 10 & Sri Lanka & 21 \\
\hline 11 & Sri Lanka & 2421 & 11 & South Africa & 17 \\
\hline 12 & Iraq & 2382 & 12 & Romania & 16 \\
\hline 13 & Romania & 2315 & 13 & Poland & 15 \\
\hline 14 & Poland & 2091 & $14=$ & Italy & 14 \\
\hline 15 & Australia & 1955 & $14=$ & Spain & 14 \\
\hline 16 & Spain & 1745 & 16 & Greece & 12 \\
\hline 17 & Sudan & 1650 & 17 & France & 11 \\
\hline 18 & Hungary & 1496 & 18 & Myanmar & 9 \\
\hline 19 & Czech Republic & 1235 & $19=$ & Czech Republic & 7 \\
\hline 20 & Bulgaria & 969 & $19=$ & Sudan & 7 \\
\hline 21 & Bangladesh & 889 & $21=$ & Belgium & 6 \\
\hline 22 & Netherlands (excluding Saba) & 846 & $21=$ & Hungary & 6 \\
\hline 23 & Russia & 806 & $21=$ & Iran & 6 \\
\hline 24 & Jamaica & 800 & $24=$ & Austria & 5 \\
\hline \multirow[t]{3}{*}{25} & Libya & 755 & $24=$ & Bulgaria & 5 \\
\hline & & & & Ghana & 5 \\
\hline & & & & Netherlands & 5 \\
\hline
\end{tabular}

to 1955 in 2014). The largest number of performance assessments was conducted on UK graduates (332), but the proportion of assessment cases on UK graduates is less than half that of the proportion on the medical register in 2013. UK graduates are underrepresented in performance assessments.

We plotted trends over time and, as illustrative examples, show the results for doctors qualified in the UK, Bangladesh, Germany, Greece, Nigeria and the EU 2004 states. The pattern of UK and Bangladesh trained doctors was similar: a steady increase in doctors joining the register until a sharp decrease between 2008 and 2009 (Figs. 1 and 2). Whereas doctors that trained in Germany, Greece, Nigeria and the EU 2004 states differed dramatically from one another in their patterns of joining the medical register (Figs. 3, 4, 5 and 6). In particular, the effects of the economic crisis are evident in the recent sharp increase in Greek trained doctors joining the UK medical register (Fig. 5).

\section{Comparing rates of performance assessments by PMQ}

We calculated the rate of performance assessments per thousand doctors, per enquiry year. Table 5 shows an inverted-U shape across time. The highest rate of performance assessments was conducted on doctors who trained in Bangladesh in 2001 and 2002 (roughly 4.5 cases per thousand per year). Doctors who trained in the UK and South Africa showed consistently low rates of performance assessments across the time period (Table 5).

After some exploratory analyses, we performed a negative binomial regression on the number of assessments and number of doctors on the register in each year by PMQ country. The data were over-dispersed compared 
Table 4 Comparing place of doctor's qualification between UK medical register and GMC's performance assessment data

\begin{tabular}{lllll}
\hline Country & $\begin{array}{l}\text { Number of registered } \\
\text { doctors in 2013 }\end{array}$ & $\begin{array}{l}\text { Absolute change on } \\
\text { register since 1996 }\end{array}$ & $\begin{array}{l}\text { Percentage change } \\
\text { on register since 1996 }\end{array}$ & $\begin{array}{l}\text { Total performance } \\
\text { assessment cases } \\
N=1111\end{array}$ \\
\hline Bangladesh & $874(0.3 \%)$ & +253 & $41 \% \uparrow$ & $23(21 \%)$ \\
Egypt & $3215(1 \%)$ & +1438 & $81 \% \uparrow$ & $45(5 \%)$ \\
Germany & $3258(1 \%)$ & +808 & $33 \% \uparrow$ & $45(5 \%)$ \\
Greece & $3077(1 \%)$ & +1791 & $139 \% \uparrow$ & $12(1 \%)$ \\
India & $25,114(10 \%)$ & +12361 & $97 \% \uparrow$ & $242(22 \%)$ \\
Iraq & $2326(0.8 \%)$ & +1417 & $156 \% \uparrow$ & $30(3 \%)$ \\
Ireland & $4020(2 \%)$ & -2689 & $40 \% \downarrow$ & 28 (3\%) \\
Italy & $2917(1 \%)$ & +1973 & $209 \% \uparrow$ & $14(1 \%)$ \\
Nigeria & $4067(2 \%)$ & +3049 & $300 \% \uparrow$ & $47(4 \%)$ \\
Pakistan & $9400(4 \%)$ & +6686 & $246 \% \uparrow$ & 61 (5\%) \\
South Africa & $5444(2 \%)$ & -880 & $14 \% \downarrow$ & $17(2 \%)$ \\
Sri Lanka & $2376(0.9 \%)$ & +82 & $4 \% \uparrow$ & $21(2 \%)$ \\
United Kingdom & $164,691(63 \%)$ & +39205 & $31 \% \uparrow$ & $332(30 \%)$ \\
a EU 2004 states & $6206(2 \%)$ & +5513 & $796 \% \uparrow$ & $33(3 \%)$ \\
EEA remainder & $7715(3 \%)$ & +4638 & $151 \% \uparrow$ & 67 (6\%) \\
Rest of the world & $14,942(6 \%)$ & +1532 & $11 \% \uparrow$ & 70 (6\%) \\
\hline
\end{tabular}

${ }^{a}$ Cyprus, Czech Rep., Estonia, Hungary, Latvia, Lithuania, Malta, Poland, Slovakia, Slovenia

to a Poisson regression, so a negative binomial regression was used. We included independent variables to cover: (1) year (modelled as a quadratic function), and (2) place of medical qualification. This allows us to control for changes over time in assessment rates and the make-up of the medical register. The model was highly significant: $\chi^{2}(17)=188, \quad p<0.0001, \quad$ pseudo- $\mathrm{R}^{2}=15 \%$. The rate of performance assessment varies significantly by where a doctor qualified and by enquiry year.

We calculated an incidence rate ratio (IRR) of performance assessment for PMQ country, with UK graduates as the baseline, controlling for enquiry year (Table 5). An IRR can be interpreted similarly to an odds

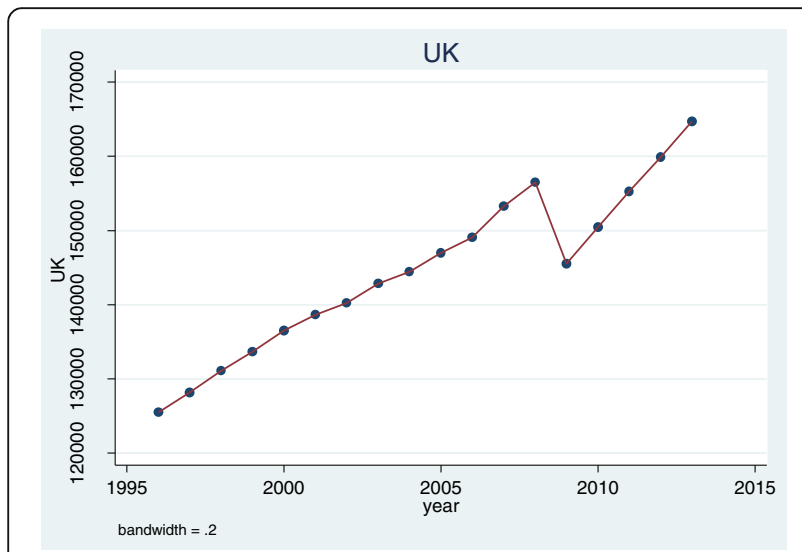

Fig. 1 Pattern of UK trained doctors joining medical register between 1996 and 2014 ratio: 1 represents no difference with UK graduates. All doctors who trained outside the UK were more likely to have a performance assessment, with the exception of South African-trained doctors. Doctors who trained in Bangladesh were 13 times more likely to have a performance assessment than UK graduates, followed by Egyptian and Nigerian trained doctors with an IRR of 8. Doctors who trained in the EU accession states and the remainder of EEA were more than 4 times likelier to have a performance assessment than UK graduates. We plot these incidence rate ratios with confidence intervals in Fig. 7. An important caveat to note is that these IRRs represent very small actual numbers of doctors given the low baseline rate.

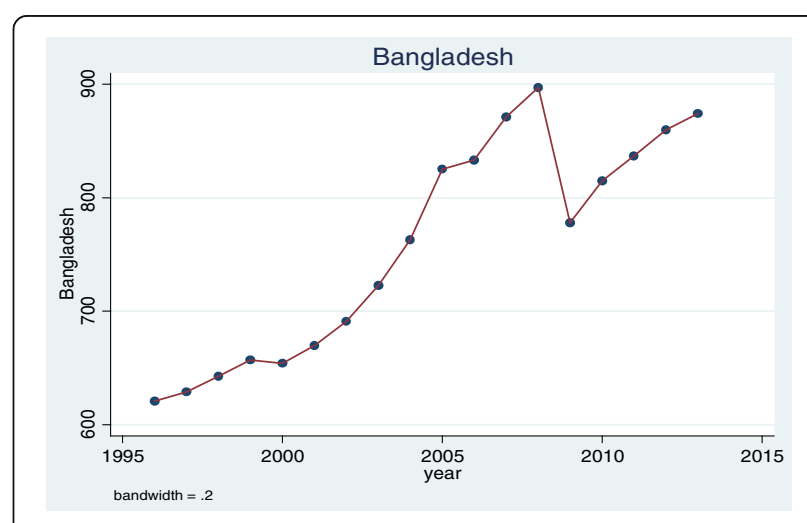

Fig. 2 Pattern of Bangladesh trained doctors joining medical register between 1996 and 2014 


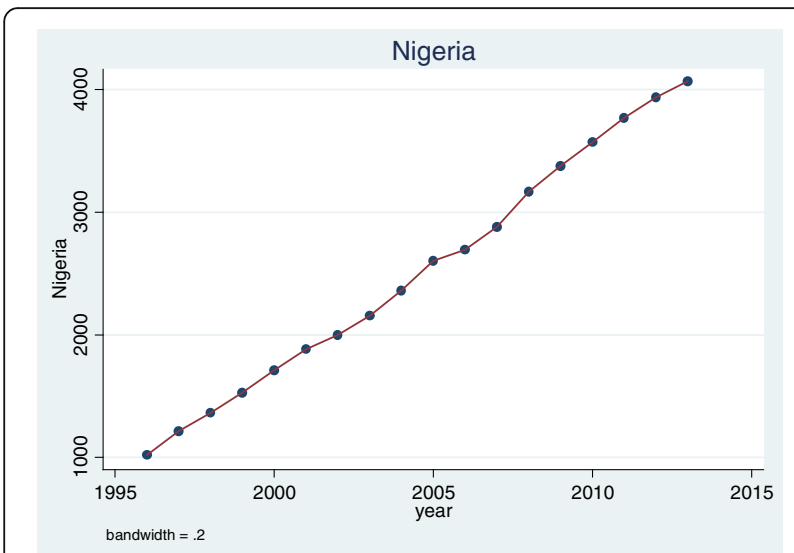

Fig. 3 Pattern of Nigerian trained doctors joining medical register between 1996 and 2014

We also did pairwise comparisons to test whether the differences in IRRs between PMQ regions were significant or not (Table 6). The rate of performance assessments conducted on UK trained doctors is significantly lower compared to doctors who qualified outside of the UK with the exception of South African-trained doctors (Table 6).

\section{Analysis of the medical register}

The GMC provided a list of all doctors who had been on the register at any time between 1996 and 2014 with sex, country of PMQ and year of PMQ. This covers 440,505 individuals. We analysed this data to identify possible confounders to our main analysis.

Using the same country coding as the previous analysis, we investigated whether PMQ region varies by these other variables. There is a significant difference by PMQ region and gender: $\chi^{2}(15)=7425, p<0.001$. Every non-UK region has more male doctors, ranging from

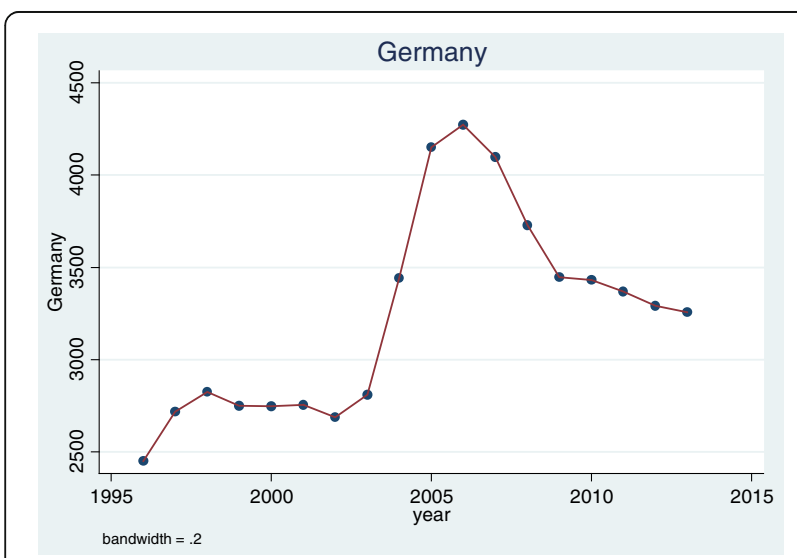

Fig. 4 Pattern of German trained doctors joining medical register between 1996 and 2014

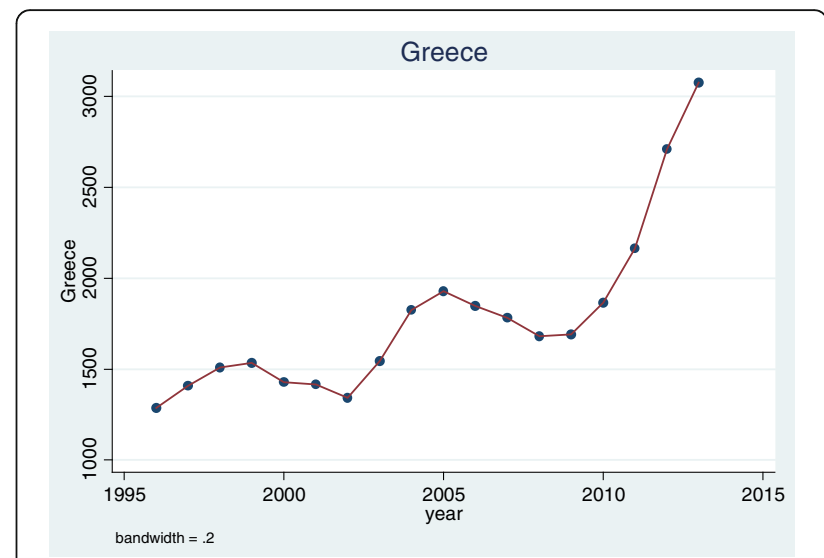

Fig. 5 Pattern of Greek trained doctors joining medical register between 1996 and 2014

86.4\% for Egypt to $58.2 \%$ for the EEA remainder category, compared to $56.6 \%$ for the UK.

If we compare PMQ country by being on the GP register, there is a significant difference: $\chi^{2}(15)=22,584, p<$ 0.001. Every non-UK region has fewer doctors on the GP register, ranging from $1.2 \%$ for Greece to $18.2 \%$ for Bangladesh and Nigeria, compared to $25.6 \%$ for the UK.

A Kruskal-Wallis test of PMQ year by PMQ country was statistically significant: $\chi^{2}(15)=18,059, p<0.001$. This means that on average, the year that doctors qualified varied by where they graduated from. For example, Irish graduates on average (median) qualified the earliest, in 1981, whereas UK graduates on average qualified in 1992. Italian trained doctors qualified the latest, 1999 on average.

\section{Discussion}

\section{Summary of main results}

The rate of performance assessment varies significantly by enquiry year and where a doctor qualified. Controlling for year, doctors who trained outside the UK were more likely to have a performance assessment, with the

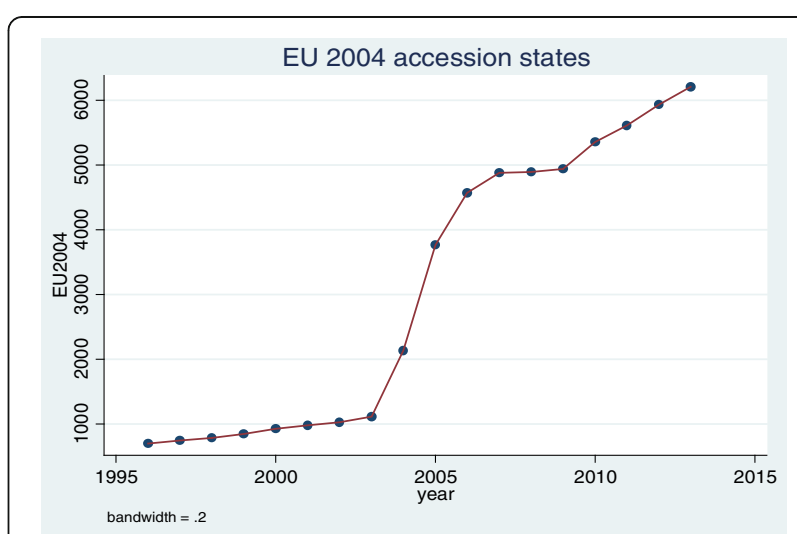

Fig. 6 Pattern of doctors who trained in a state that became part of EU in 2004 who joined medical register between 1996 and 2014 
Table 5 Heat map of rates of performance assessments by place of qualification (darker shades represent higher rates of performance assessments)

\begin{tabular}{|c|c|c|c|c|c|c|c|c|c|c|c|c|c|c|c|c|c|c|}
\hline & 1996 & 1997 & 1998 & 1999 & 2000 & 2001 & 2002 & 2003 & 2004 & 2005 & 2006 & 2007 & 2008 & 2009 & 2010 & 2011 & 2012 & 2013 \\
\hline UK & 0.01 & 0.02 & 0.07 & 0.18 & 0.23 & 0.14 & 0.15 & 0.15 & 0.14 & 0.06 & 0.17 & 0.12 & 0.19 & 0.12 & 0.15 & 0.15 & 0.11 & 0.05 \\
\hline Bangladesh & 0 & 0 & 1.56 & 1.52 & 4.59 & 4.48 & 1.45 & 0 & 2.62 & 1.21 & 1.2 & 2.3 & 2.23 & 0 & 2.45 & 2.39 & 0 & 2.29 \\
\hline Egypt & 0 & 0.51 & 0 & 2.34 & 0.89 & 1.73 & 0 & 1.66 & 0 & 0.77 & 1.9 & 0 & 2.51 & 0.71 & 1.67 & 1.31 & 0.64 & 0.62 \\
\hline Germany & 0 & 0.37 & 0.35 & 0.36 & 1.09 & 0.36 & 0.74 & 0.71 & 0.87 & 0.48 & 0.47 & 1.95 & 2.95 & 0.58 & 0.58 & 0.89 & 0.3 & 0 \\
\hline Greece & 0 & 0 & 0 & 1.3 & 0 & 0 & 0.74 & 0 & 0.55 & 0.52 & 0 & 0 & 0 & 0.59 & 0.54 & 1.85 & 0 & 0.32 \\
\hline India & 0.08 & 0.15 & 0.77 & 0.83 & 1.75 & 0.76 & 0.51 & 0.27 & 0.78 & 0.53 & 0.5 & 0.68 & 0.76 & 0.74 & 0.7 & 0.39 & 0.51 & 0.24 \\
\hline Iraq & 0 & 0 & 0.93 & 0.86 & 1.53 & 0.71 & 0.65 & 2.48 & 1.15 & 1.6 & 1 & 0.48 & 2.77 & 0.9 & 0.87 & 0.43 & 0 & 0.43 \\
\hline Ireland & 0 & 0.15 & 0.15 & 0.59 & 0 & 0.15 & 0 & 0.93 & 0.16 & 0.34 & 0.36 & 0.18 & 0.38 & 0 & 0.74 & 0.25 & 0.5 & 0.25 \\
\hline Italy & 0 & 0 & 0 & 0 & 0.84 & 0 & 0 & 0 & 0.73 & 0 & 0.64 & 1.77 & 1.74 & 0 & 0 & 0.44 & 1.2 & 0.34 \\
\hline Nigeria & 0 & 0 & 0.73 & 0.65 & 1.17 & 1.06 & 0.5 & 1.39 & 0.85 & 1.15 & 1.49 & 0.35 & 3.16 & 0.89 & 0.84 & 1.06 & 1.52 & 0.25 \\
\hline Pakistan & 0 & 0.34 & 0 & 0 & 1.45 & 1.88 & 0.48 & 0.84 & 0.7 & 0.15 & 1.5 & 0.57 & 0.67 & 0.79 & 0.62 & 0.35 & 0.11 & 0.32 \\
\hline \multicolumn{19}{|l|}{ South } \\
\hline Africa & 0 & 0 & 0 & 0.15 & 0.15 & 0.29 & 0.28 & 0 & 0.3 & 0 & 0.12 & 0 & 0.4 & 0.31 & 0 & 0 & 0.18 & 0.18 \\
\hline Sri Lanka & 0 & 0 & 0.44 & 0.44 & 1.32 & 0 & 0 & 0 & 0.77 & 0 & 0.38 & 0.77 & 0.76 & 1.71 & 0.41 & 0.42 & 1.29 & 0 \\
\hline EU 2004 & 0 & 0 & 1.28 & 1.19 & 1.08 & 0 & 0 & 0 & 0.47 & 0.53 & 1.1 & 0.41 & 0.61 & 1.22 & 0.93 & 0.18 & 0.84 & 0 \\
\hline EEA rem & 0 & 0 & 0 & 0.9 & 0.3 & 0.29 & 0.29 & 0.79 & 1.62 & 0.64 & 0.64 & 0.4 & 2.16 & 0.95 & 1.49 & 1.35 & 0.7 & 0.52 \\
\hline RoW & 0 & 0 & 0.14 & 0.36 & 0.37 & 0.23 & 0.32 & 0.12 & 0.12 & 0.13 & 0.34 & 0.42 & 0.49 & 0 & 0.43 & 0.64 & 0.48 & 0.33 \\
\hline
\end{tabular}

exception of South African trained doctors. Doctors who trained in Bangladesh were 13 times more likely to have a performance assessment than UK graduates, followed by Nigerian and Egyptian trained doctors who were 8 times more likely. German trained doctors were over represented among EEA graduates. Doctors who trained in the 2004 EU accession states and the bulk of the EEA were over 4 times more likely to have a performance assessment than UK graduates.

\section{Findings in relation to other studies}

Our findings indicate that the prevalence of GMC performance assessments differs depending on a doctor's country of qualification. Further, our data supports that of other studies that highlight doctors who trained in certain countries within and outside of the EEA perform worse than UK graduates. South African trained doctors, like UK graduates, have been found to perform better than average on part one of the Royal College of

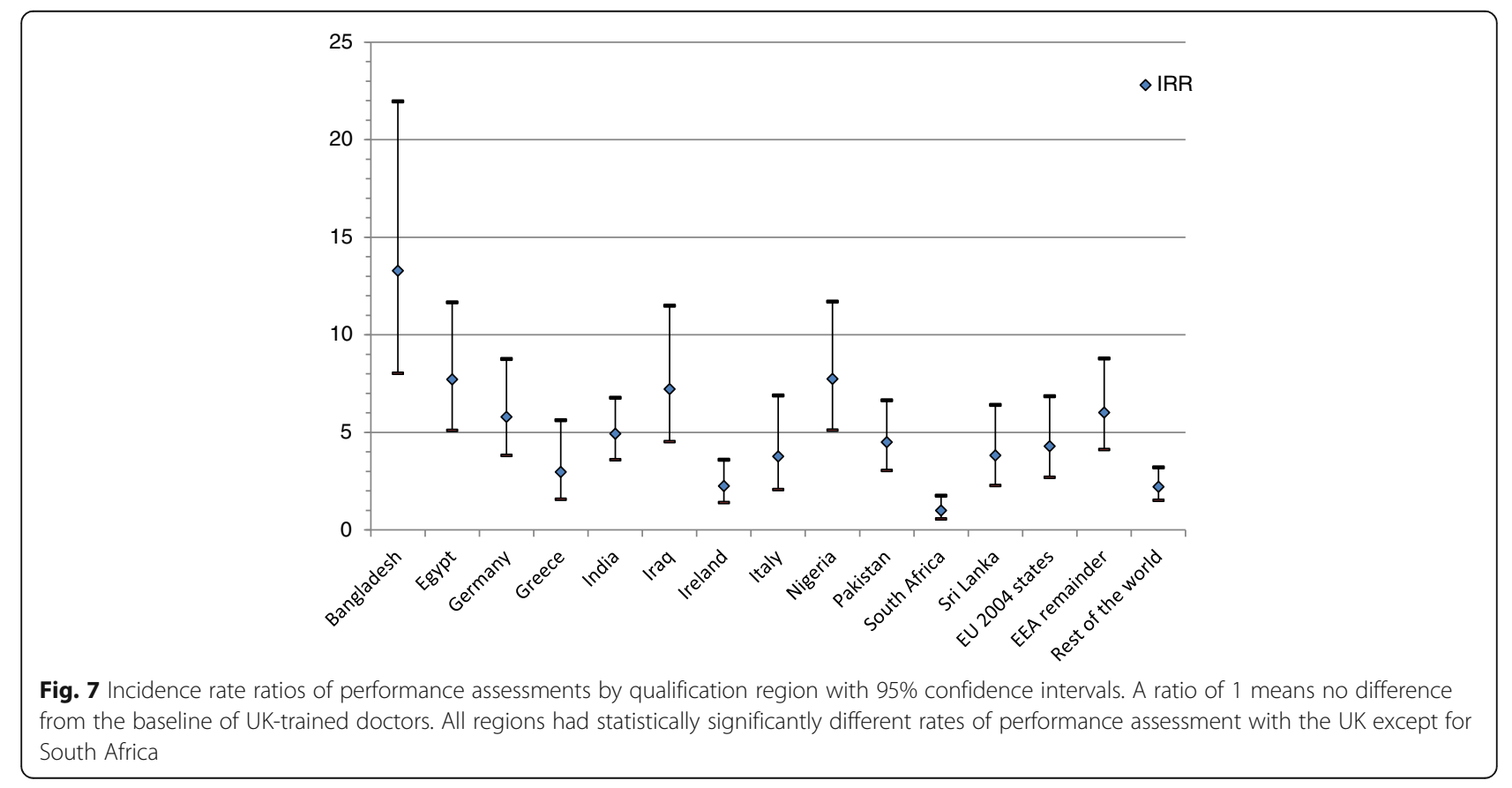


Table 6 Pairwise comparisons between each place of medical qualification

\begin{tabular}{|c|c|c|c|c|c|c|c|c|c|c|c|c|c|c|c|}
\hline $\begin{array}{l}\text { Country } \\
\text { pairwise } \\
\text { comparisons }\end{array}$ & Bangladesh & Egypt & Germany & Greece & India & Iraq & Ireland & Italy & Nigeria & Pakistan & South Africa & Sri Lanka & $\begin{array}{l}\text { EU } 2004 \\
\text { states }\end{array}$ & $\begin{array}{l}\text { EEA } \\
\text { remainder }\end{array}$ & $\begin{array}{l}\text { Rest of } \\
\text { the world }\end{array}$ \\
\hline$\overline{U K}$ & $\bullet$ & $\bullet$ & $\bullet$ & $\bullet$ & $\bullet$ & $\bullet$ & $\bullet$ & $\bullet$ & $\bullet$ & $\bullet$ & & $\bullet$ & $\bullet$ & $\bullet$ & $\bullet$ \\
\hline Bangladesh & & & $\bullet$ & $\bullet$ & $\bullet$ & & $\bullet$ & $\bullet$ & & $\bullet$ & $\bullet$ & $\bullet$ & $\bullet$ & $\bullet$ & $\bullet$ \\
\hline Egypt & & & & $\bullet$ & $\bullet$ & & $\bullet$ & $\bullet$ & & $\bullet$ & $\bullet$ & $\bullet$ & $\bullet$ & & • \\
\hline Germany & & & & & & & $\bullet$ & & & & $\bullet$ & & & & $\bullet$ \\
\hline Greece & & & & & & $\bullet$ & & & $\bullet$ & & $\bullet$ & & & $\bullet$ & \\
\hline India & & & & & & & $\bullet$ & & $\bullet$ & & $\bullet$ & & & & $\bullet$ \\
\hline Iraq & & & & & & & $\bullet$ & & & & $\bullet$ & $\bullet$ & & & $\bullet$ \\
\hline Ireland & & & & & & & & & • & $\bullet$ & $\bullet$ & & $\bullet$ & $\bullet$ & \\
\hline Italy & & & & & & & & & $\bullet$ & & $\bullet$ & & & & \\
\hline Nigeria & & & & & & & & & & $\bullet$ & $\bullet$ & $\bullet$ & $\bullet$ & & $\bullet$ \\
\hline Pakistan & & & & & & & & & & & $\bullet$ & & & & $\bullet$ \\
\hline South Africa & & & & & & & & & & & & $\bullet$ & $\bullet$ & $\bullet$ & $\bullet$ \\
\hline Sri Lanka & & & & & & & & & & & & & & & \\
\hline EU 2004 states & & & & & & & & & & & & & & & $\bullet$ \\
\hline EEA remainder & & & & & & & & & & & & & & & - \\
\hline
\end{tabular}

- indicates significant difference between the row and column categories at 5\% level

Anaesthetists' examination, while graduates from Greece, Germany and Ireland performed significantly worse [23], matching our results on performance assessments from these countries. Our results also concord with an earlier analysis of the LRMP [28]. While previous evidence has focused on comparing how UK graduates and IMGs compare in the Fitness to Practise process [20], this is the first study since Wakeford's in 2011 [28] that has explored the process on a country by country basis and the first that has been able to control for changes over time.

Perhaps one explanation is in differences in the way doctors are trained in different countries. Training in the UK has long been integrating patient contact and practical skills into early undergraduate training [32]. German medical schools have only adopted this approach more recently [33]. Questionnaire studies have also reported major differences in medical regulation among non-UK countries. One study found that in certain countries (Spain, Austria, Finland and Estonia) there was an implicit expectation that doctors maintain competence without needing to comply with formal standards. Whereas in others (Belgium, Germany, Hungary, the Netherlands, Slovenia and the UK), an explicit demonstration of continued competence is mandatory [34]. Further, when representatives from 14 EU countries were surveyed, authors concluded that the systems of licensing and registration vary so much that it creates confusion and problems in the context of the free movement of doctors. In particular, there were large differences in how fitness to practise is conceptualised and some countries showed weaknesses in their systems that should identify doctors who are unfit to practise [35]. As well as IMGs, European graduates are more likely to experience difficulty in adapting to a very different healthcare context than the one in which they trained [21]. Another unanswered question is how representative doctors who choose to move to the UK are compared to doctors who stay practicing in the country in which they trained.

There is also a question around who gets complained about to the GMC [16]. Non-UK trained graduates, including those from the EEA as well as minority ethnic doctors, are more vulnerable to being complained about than white UK graduates [36]. It is possible that an over representation of non-UK trained doctors is due to prejudice. Unconscious bias against foreign-born doctors has been shown experimentally among students [37] and staff from ethnic minority backgrounds working in the NHS are more likely to report harassment and discrimination from their patients and colleagues [38]. Similar issues with discrimination by patients and colleagues were seen in a US survey of Muslim doctors [5].

\section{Meaning of the study}

Rates of performance assessments differ depending on the country or region a doctor trained in. However, without further investigation, it is unclear as to whether this represents a true difference in doctors' competence. Rates of performance assessments overall are very low and absolute differences between countries are tiny. Problems leading to an investigation may not reflect poor medical competence, but be due to poorer English language skills or lack of knowledge of the UK's health 
service. Performance investigation is not a reflection of poor performance alone but also of complaints patterns, which could indicate prejudice in the system.

Our findings suggest concern not only with IMGs but also European-trained doctors given that they were significantly more likely to have a GMC performance assessment than doctors trained in the UK, South Africa and our "rest of the world" category. One qualitative study found that European trained doctors reported similar difficulties to IMGs when adapting to practising medicine in the UK's healthcare setting and medical regulatory system [39]. European law has prevented the selective testing of doctors trained in an EEA country that is different to how UK trained doctors are tested. There is currently no mandatory assessment process to check the competence of EEA medical graduates before their UK medical licence is granted, although we note that EEA graduates who have not done the PLAB broadly did no worse than IMGs who have done the PLAB. The GMC is going to introduce a medical licensing assessment that will be mandatory for UK graduates and IMGs prior to their registration. It was unlikely that the elements of this planned assessment could have been enforced on European graduates given European laws around free movement $[19,40]$. Currently, the GMC can only seek evidence of sufficient English language skills in European graduates and can refuse to grant a licence to practise where this is not provided [41]. All this may change in a post-Brexit regulatory environment that is yet to be determined. Further analysis of this topic is needed rapidly to inform decision making.

We also note that not all overseas trained doctors were more likely to have a performance assessment. South African trained doctors were no more likely to have a performance assessment than UK trained doctors. While there were too few Hong Kong trained doctors to include separately in the main analysis-their numbers have decreased from 2730 to 614 between 1996 and 2013-we note none had a performance assessment. Therefore it is a matter of further investigation as to why doctors from certain countries or regions might be more at risk than others of being investigated by the GMC due to performance concerns.

\section{Strengths and weaknesses of the study}

This is the first study to explore whether place of medical qualification on a country by country basis affects the likelihood of having a GMC performance assessment. We urge caution in the interpretation of our findings. It is not true that all doctors who qualified outside the UK are more likely to have a GMC performance assessment and those doctors who have an investigation for performance concerns represent a tiny minority of overseas trained doctors. While the incidence rate ratios appear large for some PMQ countries, the number of doctors investigated for each PMQ country is low and absolute differences between countries are tiny. The results are further complicated because a performance investigation is not a reflection of poor performance alone but also of who gets complained about and how severe the complaint is. A proportion of doctors under performance investigation are found to be fit to practise. It is also likely that some doctors may show performance concerns but that they are being managed locally and do not meet the GMC's threshold for an investigation. To unpack these factors requires data that we did not have on referral patterns by PMQ country or final outcome of the investigation.

We know that doctors' sex [42] and age [43] affect performance and those factors vary by where a doctor trained in our analysis of the register data. We also know that complaints vary by specialty, which also varies by where a doctor trained. We have not been able to adjust for these confounders. Therefore differences between PMQ countries may be explainable in terms of the doctors who trained in a particular country having a different profile in terms of sex, age and specialty.

\section{Conclusions}

From 1996 to 2013, doctors that trained outside of the UK, including EEA countries, had significantly higher rates of GMC performance assessments than UK-trained doctors. The reasons for this are unclear without further investigation. Poor performance can manifest itself in many forms some of which include poor clinical knowledge, English language skills and a misunderstanding of patient's culture or the UK's healthcare settings. Factors such as sex, age and specialty of doctors are likely to be confounding variables. If differences persisted after controlling for these factors, it could reflect true differences in competency, standards of medical training and/or certification between different countries, or it could reflect different treatment of this group by society and employers [16]. Whether differences by country of training reflect differences in the ability of some doctors, or biases in systems of performance evaluation, this is an important phenomenon that further research needs to explain.

There may be implications for transnational agreements on freedom of movement of healthcare professionals, and for what testing is required by national governments of individuals trained elsewhere. With the UK having to negotiate new arrangements after exiting the EU, such questions have become more urgent. Research in the UK can also inform the situation in other countries facing similar political, economic and social pressures. In the meantime, patients should be reassured that the vast majority of doctors working in the UK, irrespective of where they trained, are competent, and indeed highly skilled. Further, the NHS could not function without foreigntrained doctors or other healthcare professionals. 


\section{Abbreviations}

EEA: European Economic Area; EU: European Union; GMC: General Medical Council; IMG: International Medical Graduate; IRR: Incidence rate ratio; LRMP: List of Registered Medical Practitioners; NHS: National Health Service; PLAB: Professional and Linguistics Assessments Board; PMQ: Primary medical qualification; ROW: Rest of the world; UK: United Kingdom

\section{Funding}

This study was funded by the UK's medical regulator, the GMC. They provided the data and approved the manuscript's final version for journal submission.

\section{Availability of data and materials}

Due to our confidentiality agreement with the GMC, no additional data or materials are available.

\section{Authors' contributions}

All authors contributed to the study's design. LM and HWWP performed the data analysis and LM wrote the first draft of the manuscript. All authors contributed to the revised draft manuscripts and approved its final version.

\section{Competing interests}

All authors have completed the Unified Competing Interest form at www.icmje.org/coi_disclosure.pdf (available on request from the corresponding author) and declare that LM, AS and JD work on a long-term research project within $U C L$ that is externally funded by the GMC, who supported this work. HWWP acts as an external consultant for this research collaboration between UCL and the GMC.

\section{Consent for publication}

\section{Not applicable.}

\section{Ethics approval and consent to participate}

The study received ethical approval from UCL Research Ethics Committee, ref $6281 / 001$. Data was made available by the GMC; consent from individuals was not sought.

\section{Publisher's Note}

Springer Nature remains neutral with regard to jurisdictional claims in published maps and institutional affiliations.

\section{Author details}

'University College London Medical School, Royal Free Hospital, room GF/ 664, Hampstead, London NW3 2PF, UK. ${ }^{2}$ UCL Institute of Health Informatics, 222 Euston Road, London NW1 2DA, UK. ${ }^{3}$ Royal College of Physicians, 11 St Andrews Place, Regent's Park, London NW1 4LE, UK.

Received: 1 July 2016 Accepted: 15 March 2017

Published online: 04 April 2017

\section{References}

1. Appleby J. Healthcare and the EU: Brexit, Bremain ... or Brundecided? BMJ. 2016;353:i2328.

2. Bidwell $P$, Humphries N, Dicker P, Thomas S, Normand C, Brugha R. The national and international implications of a decade of doctor migration in the Irish context. Health Policy. 2013;110(1):29-38.

3. Gilnos I. Going beyond numbers: A typology of health professional mobility inside and outside the European Union. Policy Society. 2014;33(1):25-37.

4. Aluttis C, Bishaw T, Frank MW. The workforce for health in a globalized context global shortages and international migration. Glob Health Action. 2014;7:23611.

5. Padela Al, Adam H, Ahmad M, Hosseinian Z, Curlin F. Religious identity and workplace discrimination: A national survey of American Muslim physicians. AJOB Empirical Bioethics 2015. DOI: 10.1080/23294515.2015.1111271

6. Sun LH. American Muslim doctors feel greater scrutiny, even patients' suspicions. The Washington Post, 11 December 2015. https://www. washingtonpost.com/news/to-your-health/wp/2015/12/11/american-muslimdoctors-feel-greater-scrutiny-even-patients-suspicions/. Accessed 21 Mar 2017

7. Tobias AJ Group including Cleveland doctors organizing protest march over Donald Trump's Muslim rhetoric during Republican National Convention Cleveland.com, 20 May 2016, http://www.cleveland.com/rnc-2016/index.ssf/ 2016/05/group_of_cleveland_physicians.html. Accessed 21 Mar 2017.
8. Godlee F, Abbasi K, Gulland A, Coombes R. Why doctors should vote to remain in the EU on 23 June. BMJ. 2016:353:i3302.

9. Gulland A. What would the NHS look like if the UK left the EU? BMJ. 2016 353:i3027.

10. Gulland A. Brexit plan has few details on securing health workers from abroad. BMJ. 2017:356:j614.

11. Klein J. Migration of Central Eastern European Physicians to Germany: An Empirical Description of the Field. In: Pilati M, Sheikh H, Sperotti F, Tilly C, editors. How Global Migration Changes the Workforce Diversity Equation. Newcastle upon Tyne: Cambridge Scholars Publishing; 2015. p. 101-25.

12. General Medical Council. The State of Medical Education and Practice in the UK. 2013.

13. Sturrock A, Conlon L, Hatch D, Dacre J. The GMC's Tests of Competence what happens now? Clin Teach. 2006;3(1):9-12.

14. Sales D, Sturrock A, Boursicot K, Dacre J. Blueprinting for clinical performance deficiencies - Lessons and principles from the General Medica Council's fitness to practise procedures. Med Teach. 2010;32:e111-4.

15. Dacre J, Potts HWW, Sales D, Spencer H, Sturrock A. The development of a new method of knowledge assessment: Tailoring a test to a doctor's area of practice. Acad Med. 2009;84(8):1003-7.

16. Esmail A, Simpson J. International medical graduates and quality of care. BMJ. 2017;356:j574.

17. Esmail A, Roberts C. Academic performance of ethnic minority candidates and discrimination in the MRCGP examinations between 2010 and 2012: Analysis of data. BMJ. 2013;347:f5662.

18. McManus IC, Wakeford R. PLAB and UK graduates' performance on MRCP(UK) and MRCGP examinations: data linkage study. BMJ. 2014:348: g2621.

19. General Medical Council. The State of Medical Education and Practice in the UK. 2014.

20. Humphrey C, Hickman S, Gulliford MC. Place of medical qualification and outcomes of UK General Medical Council "fitness to practise" process: cohort study. BMJ. 2011;340:d1817.

21. Legido-Quidley H, Salibab V, McKee M. Exploring the experiences of EU qualified doctors working in the United Kingdom: A qualitative study. Health Policy. 2015:119:494-502.

22. Dyer $\mathrm{O}$. Registrar who used excessive force in forceps delivery is struck off the medical register. BMJ. 2008:336(7651):983.

23. Watmough S, Bowhay A. An evaluation of the impact of country of primary medical qualification on performance in the UK Royal College of Anaesthetists' examinations. Med Teach. 2011;33:938-40.

24. General Medical Council. Primary Medical Qualification. FTP Fact Sheet. 2009

25. General Medical Council. Primary Medical Qualification. FTP Fact Sheet. 2010.

26. General Medical Council. Primary Medical Qualification. FTP Fact Sheet. 2011

27. General Medical Council. Primary Medical Qualification. FTP Fact Sheet. 2012

28. Wakeford R. Who gets struck off? BMJ. 2011;343:d7842. doi:10.1136/bmj. d7842.

29. Tsugawa $Y$, Jena AB, Orav EJ, Jha AK. Quality of care delivered by general internists in US hospitals who graduated from foreign versus US medical schools: observational study. BMJ. 2017;356:j273.

30. Garibaldi RA, Subhiyah $R$, Moore ME, Waxman $H$. The In-Training Examination in Internal Medicine: An analysis of resident performance over time. Ann Intern Med. 2002;137(6):505-10.

31. GMC 2014: Council GM. Guidance on making decisions on voluntary erasure applications. GMC. 2014. http://www.gmc-uk.org/voluntary_erasure_ guidance.pdf_25416412.pdf. Accessed 05/01/2017 2017

32. Harden R. The integration ladder: a tool for curriculum planning and evaluation. Med Educ. 2000:34:551-7.

33. Chenot JF. Undergraduate medical education in Germany. GMS German Med Sci. 2009:7:Doc02

34. Sole M, Dimitra P, Risso-Gill I, Doring N, Busse R, McKee M, Legido-Quigley H. How do medical doctors in the European Union demonstrate that they continue to meet criteria for registration and licencing? Clin Med. 2014; 14(6):633-9.

35. Kovacs E, Schmidt AE, Szocska G, Busse R, McKee M, Legido-Quigley H. Licensing procedures and registration of medical doctors in the European Union. Clin Med. 2014;14(3):229-38. 
36. General Medical council. The State of Medical Education and Practice in the UK. 2015.

37. Louis WR, Lalonde RN, Esses VM. Bias against foreign-born or foreign-trained doctors: experimental evidence. Med Educ. 2010;44:1241-7. doi:10.1111/j. 1365-2923.2010.03769.x.

38. NHS England. NHS Workforce Race Equality Standard: 2015 Data Analysis Report for NHS Trusts. NHS Equality and Diversity Council. 2016. https:// www.england.nhs.uk/wp-content/uploads/2014/10/WRES-Data-AnalysisReport.pdf. Accessed 21 Mar 2017.

39. Slowther A, Lewando Hundt GA, Purkis J, Taylor R. Experiences of non-UKqualified doctors working within the UK regulatory: a qualitative study. J R Soc Med. 2012;105:157-65. doi:10.1258/jrsm.2011.110256.

40. Gulland A. GMC proposes single test for all doctors wishing to work in UK. BMJ. 2015;350:h3094.

41. Rimmer A. Language tests for EU doctors set to start in June. BMJ Careers. 2014. http://careers.bmj.com/careers/advice/Language_tests_for_EU_ doctors_set_to_start in_June. Accessed 21 Mar 2017.

42. Unwin E, Woolf K, Wadlow C, Potts HWW, Dacre J. Sex differences in medico-legal action against doctors: a systematic review and meta-analysis. BMC Med. 2015;13:172. doi:10.1186/s12916-015-0413-5.

43. Mehdizadeh L, Sturrock A, Dacre J. Are the General Medical Council's Tests of Competence fair to long standing doctors? A retrospective cohort study. BMC Med Educ. 2015;15:80. doi:10.1186/s12909-015-0362-x.

Submit your next manuscript to BioMed Central and we will help you at every step:

- We accept pre-submission inquiries

- Our selector tool helps you to find the most relevant journal

- We provide round the clock customer support

- Convenient online submission

- Thorough peer review

- Inclusion in PubMed and all major indexing services

- Maximum visibility for your research

Submit your manuscript at www.biomedcentral.com/submit
Biomed Central 